\title{
Aleksandra Łuczak \\ Koźmiński University \\ SCAFFOLDING THE WRITING COMPONENT OF THE ENGLISH FOR LAW SYLLABUS AT UNIVERSITY
}

\begin{abstract}
The present paper is intended to be a practical guide for teachers who need to run writing for law classes for pre-experienced law students with no or little experience of academic or legal writing. It provides the teachers with advice on how to teach students to draft modern documents by sequencing and selecting the content that reflects the needs of practising lawyers. It shows how legal writing stems from academic and general writing. Overlapping or common elements of academic and legal writing are identified and sequenced in order to create an introductory base for writing for legal purposes.

Types of texts that lawyers draft have been selected and used as the scaffolding for writing tasks specially designed to suit the students' proficiency and expertise.
\end{abstract}

Keywords: Legal English, ESP, academic writing, writing for legal purposes, plain English, syllabus design.

You are not a Romeo, you are a lawyer

Anonymous

Proponents of the plain language movement consider legal drafting to be synonymous with poor writing. One of the first critics of legal English in its pure form, so called legalese, was Lord Broughman who suggested changes not only in the substance of law, but also in its language in the mid XIX century (Law Review, 1845:405). Around the same time, Charles Dickens, who was formerly a law clerk but gave up the profession because he found it dull, in "Bleak House" mocked his character's, Sir Leicester's, liking for the legal repetitions and prolixities (2009:14).

However, it is Stuart Chase who is often mentioned as the first promoter of plain English when he complained about "gobbledygook" in his book The Power of Words published in 1953 (Redish, 1985; Shriver, 1997). His criticism was well received, since the second half of the twentieth century 


\section{Aleksandra Luczak}

with its developing consumer movement created the need for clear legal language, which would be understood at first reading by everyman, irrespective of his/her education and knowledge. In addition, new means of communication, which emerged and developed during this time, also encouraged the need for plain, precise and comprehensible meaning in texts.

Plain language is a variant of a national language recommended to authors and institutions producing texts for the general public. The idea of the plain language movement is to include into public life, groups of citizens that are excluded due to their inability to comprehend official texts, e.g. administrative, legal, journalistic, corporate, advertising, etc. Martin Cutts (1998), a research director of the Plain Language Commission in the United Kingdom, defines plain English as

the writing and setting out of essential information in a way that gives a cooperative, motivated person a good chance of understanding the document at the first reading, and in the same sense that the writer meant it to be understood.

In the KISS, i.e. Keep It Short and Simple era, lengthy, verbose, loaded with technicalities legalese, resembling Shakespeare's style of writing, would seem to be a thing of the past. However, contemporary legal English still has features, which due to historical influences, derive from French and Latin and reflect the urge of many writers to sound sophisticated and educated by the use of too many unnecessary, empty words. Generations of legal writers educated on legal texts drafted by other lawyers copy the antique style loaded with long sentences, bad punctuation, foreign syntax, archaic words, lists of synonyms, passive voice structures, and technical vocabulary. They obscure the meaning, cause confusion and misunderstandings, are wordy, unclear, pompous and dull (Melinkoff, 1963:24). The kind of text cited below, even though produced in 1915 can still be encountered in legal writing:

And in the outset we may as well be frank enough to confess, and, indeed, in view of the seriousness of the consequences which upon fuller reflection we find would inevitably result to municipalities: in the matter of street improvements from the conclusion reached and announced in the former opinion, we are pleased to declare that the arguments upon rehearing have convinced us that the decision upon the ultimate question involved here formerly rendered by this court, even if not faulty in its reasoning from the premises announced or wholly erroneous in conclusions as to some of the question incidentally arising and necessarily legitimate subjects of discussion in the decision of the main proposition, is, at any rate, one which may, under the peculiar circumstances of this case, the more justly and at the same time, upon reasons of equal 
cogency, be superseded by a conclusion whose effect cannot be to disturb the integrity of the long and well-established system for the improvement of streets in the incorporated cities and towns of California not governed by freeholders' charters. (Chase v. Kalber, 153:397-398 (Cal. 1915))

The above 178-word, one-sentence court decision is the equivalent of a 6word sentence meaning: Last time we made a mistake. Contemporary law students, however still read texts of the above complexity and automatically and subconsciously adopt the same style of intricate, wordy and highly formalized writing. Acquiring that kind of parlance in fact constitutes part of legal education.

The problem of unintelligibility has always been the case with English legal language. With the Roman invasion in 55 BC Latin, a lingua franca of the time, was introduced to Great Britain and legal texts were drafted in it. After the Battle of Hastings (1066) and the Norman invasion, French became the language of legal documents in Britain for 300 years, although the people of Britain still spoke English which was never used in legal matters. The first reform came with the Statute of Pleading (1356) which stipulated that

all Pleas which shall be pleaded in [any] Courts whatsoever, before any of his Justices whatsoever, or in his other Places, or before any of His other Ministers whatsoever, or in the Courts and Places of any other Lords whatsoever within the Realm, shall be pleaded, shewed, defended, answered, debated, and judged in the English Tongue, and that they be entered and inrolled in Latin.

Since then English gradually started to be adopted for more and more kinds of legal documents, but statutes began to be written in English alone, only after 1489. Legal writing has been criticised ever since.

The plain language standard has already been legally enforced in several countries. In the USA President Obama signed the Plain Writing Act of 2010 on October 13, 2010. According to this law, federal agencies must communicate with the public in a way that the public can understand and use. On January 18, 2011, Obama issued a new Executive Order, "E.O. 13563 - Improving Regulation and Regulatory Review" which obliges the American regulatory system to make sure that their regulations are accessible, consistent, written in plain language, and easy to understand. Other countries where plain language is mandatory include Canada, Australia, New Zealand, Germany and the UK. An interesting case study from Portugal - a country with the highest illiteracy rate in the EU is presented in Sandra Fisher-Martin's talk entitled "The right to understand" on TED.com (http://blog.ted.com/2011/11/06/the-right-to-under 


\section{Aleksandra Luczak}

stand-sandra-fisher-martins-on-ted-com/). The above examples show that plain language is a standard being applied in many countries. In Poland the idea of plain language was popularised in 2012 when the Plain Polish Section (pol. Pracownia Prostej Polszczyzny) was set up at the Faculty of Polish at the University of Wroclaw, Poland with the main aim of preparing a Polish version of plain language - a communication style that is comprehensible to a mass audience.

\section{Plain language and teaching}

Writing, or legally speaking - drafting, is considered the most important language skill for lawyers and at the same time their biggest weakness. Good writing is the mark of a good lawyer. Lawyers, who write in a coherent and logical way, improve their credibility and their attractiveness to potential employers, which is an especially important tip for graduates. On the other hand, inability to draft, alongside commercial awareness, is often mentioned as the biggest lack of university graduates.

Legal writing therefore, requires special attention and intensive development during legal English courses. Plain English constitutes the appropriate model, which can be contrasted with the legalese which law students and graduates have to read, understand and work on. In this sense, plain English becomes a sort of lingua franca in the legal English classroom and the guidelines for writing in plain English can form the base of any writing course for legal purposes. The guidelines for writing in plain English (e.g., Butt \& Castle, 2006; Garner, 2001; Haigh, 2012; Rylance, 1994) correspond to the rules of effective writing for any special purposes, including legal, academic, business, medical etc.

In Legal Writing in Plain English. A Text with Exercises Garner (2001) draws up a comprehensive list of principles for plain English writing including legal writing, analytical and persuasive writing, legal drafting, document design and continued improvement. The exercises accompanying the book can be accessed on http://press-pubs.uchicago.edu/garner/. All these exercises are based on authentic excerpts of legal writing which are used as a basis for paraphrasing, redrafting and editing in plain English.

Most of these principles help develop the transferable abilities typical of writing which might constitute the scaffolding for the future development of the writing skill, irrespective of the purpose. Plain English is considered the equivalent of good English writing. Therefore, the guidelines for writing in plain English should be included in each writing course, since 
they comprise the rules for producing well structured, comprehensible and concise texts.

According to Garner (2001) the skills which law students and graduates need to develop if they wish to draft texts in plain English include:

I. Planning:

a. using a nonlinear, whirlybird (i.e. resembling the mind map) approach is recommended for lawyers;

b. arranging the material in a logical sequence, e.g. using chronology when presenting facts;

c. dividing the documents into sections, and sections into smaller parts;

d. adding headings for the sections and subsections.

II. Paragraphing and organizing writing:

a. beginning each paragraph with a topic sentence;

b. linking paragraphs and signposting within paragraphs;

c. limiting the length of paragraphs to $3-8$ sentences/150 words;

d. knowing the reader - an ordinary person and not a sophisticated lawyer;

e. applying correct punctuation.

III. Phrasing and paraphrasing (legalese into plain English):

a. avoiding verbosity; reducing the average length of a sentence to 20 words;

b. relying on $\mathrm{S}-\mathrm{V}-\mathrm{O}$ word order;

c. favouring active over passive voice;

d. creating lists with parallel phrasing for parallel ideas;

e. avoiding multiple negatives;

f. understanding legalese but replacing it with plain English alternatives, e.g. "hereinafter Seller" with "the Seller", "prior to" with "before", "in the event that" with "if";

g. minimizing the use of "to be", e.g. court is in agreement, fines are dependent, judge is of the opinion...;

h. avoiding nouns created from verbs, e.g. conduct an examination of, make provision for, take into consideration...;

i. shortening wordy phrases, e.g. "a number of" to "many", "at the time when" to "when", "subsequent to" to "after", "the majority of" to "most".

The model for writing that is usually cited by supporters of the Plain English Movement is George Orwell, whose simple style and text structure may serve as an excellent example as in the sample below from 1984 (Orwell, 1949:123): 


\section{Aleksandra Luczak}

A Party member lives from birth to death under the eye of the Thought Police. Even when he is alone he can never be sure that he is alone. Wherever he may be, asleep or awake, working or resting, in his bath or in bed, he can be inspected without warning and without knowing that he is being inspected.

Nothing that he does is indifferent. His friendships, his relaxations, his behaviour towards his wife and children, the expression of his face when he is alone, the words he mutters in sleep, even the characteristic movements of his body, are all jealously scrutinized. Not only any actual misdemeanour, but any eccentricity, however small, any change of habits, any nervous mannerism that could possibly be the symptom of an inner struggle, is certain to be detected. He has no freedom of choice in any direction whatever. On the other hand his actions are not regulated by law or by any clearly formulated code of behaviour.

In 1946 in his essay "Why I write", Orwell wrote that good prose is like a window pane and a year earlier he published his manifesto entitled "Politics and the English Language" in which he criticised the vague, pretentious, Latinised style used in politics and public speeches and formulated six elementary rules of good writing (Orwell, 1945/2013:19):

a. Never use a metaphor, simile, or other figure of speech which you are used to seeing in print.

b. Never use a long word where a short one will do.

c. If it is possible to cut a word out, always cut it out.

d. Never use the passive where you can use the active.

e. Never use a foreign phrase, a scientific word, or a jargon word if you can think of an everyday English equivalent.

f. Break any of these rules sooner than say anything outright barbarous. Since not only law students need writing skills, others following business English courses might find the advice of David Ogilvy - an iconic businessman and original "Mad Man" - convincing:

a. The better you write, the higher you go in Ogilvy \& Mather. People who think well, write well.

b. Woolly minded people write woolly memos, woolly letters and woolly speeches.

c. Good writing is not a natural gift. You have to learn to write well. Here are 10 hints:

d. Read the Roman-Raphaelson book on writing. Read it three times.

e. Write the way you talk. Naturally.

f. Use short words, short sentences and short paragraphs.

g. Never use jargon words like reconceptualize, demassification, attitudinally, judgmentally. They are hallmarks of a pretentious ass. 
Scaffolding the Writing Component of the English for Law Syllabus...

h. Never write more than two pages on any subject.

i. Check your quotations.

j. Never send a letter or a memo on the day you write it. Read it aloud the next morning - and then edit it.

$\mathrm{k}$. If it is something important, get a colleague to improve it.

1. Before you send your letter or your memo, make sure it is crystal clear what you want the recipient to do.

m. If you want ACTION, don't write. Go and tell the guy what you want. (Ogilvy, 2012:70).

\section{Plain language and syllabus design}

In the English for Law syllabus design process the most difficult part is the target analysis, i.e. defining the skills that the learners should have gained by the end of the course. In order to identify these skills, the future situation in which the foreign language will be used should be researched, as first described in 1978 by John Munby.

An attempt to identify the target needs of lawyers has been undertaken in a Leonardo da Vinci project, CEF Professional. The project was carried out in 2005/2006 by eleven partners from Finland, Bulgaria, Hungary, Germany, the Netherlands and Poland and aimed to describe the language needs of seven professional groups who were secondary school, vocational college and university graduates, employed in the areas of health care, business, engineering and law (www.cefpro.org, The Teacher, 4, 2007:37).

Research in the area of law was conducted among ten young law professionals who worked for international law firms in Warsaw, Poland, and who described their knowledge of English as good or very good, which on the basis of the researchers' observations was classified as Level B2(+) CEFR. The research produced a list of areas of law, within which young lawyers communicate in English. The list included: commercial law, company law, competition law, banking law, tax law, employment law, real property law, capital law and civil law.

The project aimed at unveiling what professional skills need to be practised with university law students and produced a very detailed list of these skills, classified according to competences which can be summarised under five question-headings dealing with what lawyers read, write, listen to, when lawyers speak and what else they do. For the purposes of this paper, these writing skill findings will be presented in detail. The CEF Pro- 


\section{Aleksandra Luczak}

fessional project identified the following documents as those which lawyers draft most often:
a. case-related letters/e-mails;
b. formal letters of advice;
c. memoranda;
d. contracts, contract clauses and agreements (lease, trade, sale, loan);
e. legal opinions;
f. court filings (writs);
g. case briefs and reports for supervisors;
h. corporate documentation.

Other writing related activities identified by CEF Professional comprise translating parts of legal documents and contracts, modern legal correspondence, summarizing various legal texts and switching between formal and informal codes.

The above findings supplement the comments provided by the "Magic Circle", i.e. leading international law firms operating around the world that include: Allen \& Overy, Clifford Chance, Linklaters, Freshfields Bruckhaus Deringer and Slaughter and May in research conducted by Catherine Mason from Global Legal English and presented during her workshop for students of Kozminski University on 18 May 2010. "Magic Circle" respondents stressed that the weakest point of law graduates who begin to work for them is the inability to draft legal documents in English.

Similar conclusions were drawn from Ph.D. research conducted by the author of this article among young professionals who use foreign languages at work. They identified their weakest points as speaking and writing. They also stressed the importance of developing specialist terminology, as it greatly facilitates communication in the workplace.

For the purpose of this article the author has conducted several additional interviews with Kozminski employees who used to work for "Magic Circle" firms in the past. Their expertise has allowed the author to draw up a list of documents used and drafted by lawyers on a daily basis which comprises:

a. e-mails used in day-to-day correspondence;

b. legal memoranda which resemble and fulfil the role of reports, such as the sample available on Clifford Chance website: http://www.clifford chance.com/publicationviews/publications/2011/09/doing_business_in angola.html. In order to avoid confusion the term "legal memoranda" will be used to refer to reports mentioned in this point as opposed to "memos" denoting standard, internal messages used for communication in companies; 
Scaffolding the Writing Component of the English for Law Syllabus...

c. English contracts for which lawyers use templates, but each firm will have its own templates;

d. Polish contracts (e.g. sale or lease contract) translated into English to be presented as models;

e. briefs which are in fact short legal memoranda;

f. letters (e.g. reminder letter, complaint, motivational);

g. law suits which are rarely drafted according to templates as they are case specific, but contain parts which are fixed, e.g. petitum (particulars) or the statement of claim.

Law graduates need very practical linguistic skills. Therefore, language accuracy and ability to draft legal documents in plain English are crucial. One of the skills that recruiters test when screening applications, and at interview, is a candidate's spelling, punctuation and the ability to use correct grammar. An application littered with mistakes is an immediate turn-off and may not be considered because of this, advises Matt Bryan, graduate recruitment officer, Trowers \& Hamlins on www.targetjobs.co.uk. The most challenging language problems which all law students have and must overcome are: the correct use of prepositions and collocations. Polish students will also have to concentrate on articles, countable and uncountable nouns and development of the plain language writing skill.

Writing and translation skills can be tested during job interview tasks in order to assess the level of the candidate's language skills and therefore applicants can expect some very practical tasks, e.g.:

a. Translate an indemnity clause from a commercial contract;

b. What is wrong with the sentence: "Thank you for your e-mail from 25 May";

c. What types of business can you set up in Poland and how do you translate their names into English?

The above findings imply that the development of the writing skill, i.e. drafting should constitute the core of the English for Law syllabus from the very beginning of the course. However, since university teachers usually deal with pre-experienced learners, it is not possible to engage the students in highly specialist writing activities. The early stages of any English for Law course should concentrate on the development of study skills as in the case of any ESP syllabus, since such skills as summarizing, translating or defining are used consistently across disciplines.

A comprehensive list of study skills and activities may be long and detailed (Jordan 1997, Wallace 2004). For the purpose of this paper let us concentrate on and select only those transferable abilities typical of writing, which might constitute the scaffolding for the future development of legal 


\section{Aleksandra Luczak}

writing. At the beginning of the English for Law course students may be given practice in the development of purely academic writing with emphasis on:

a. planning, writing drafts, revising;

b. paragraphing and organising writing;

c. the use of linking words;

d. punctuation;

e. paraphrasing;

f. using quotations, footnotes and drawing up bibliography.

The development of the above listed skills will equip learners with the knowledge and practical skills they might need in the future, no matter what careers they decide to follow. Acquiring these skills will facilitate their writing if they decide to sit any international certificate examinations in English, choose to continue their education in an academic institution where English is the medium of instruction or attempt to submit papers for international conferences, since they will help them produce well-organized, adequately developed paragraphs and whole papers written in standard, modern English. The academic writing stage would seem to be a natural and practical stage, leading students to more sophisticated and demanding areas of legal or business writing, for which they need to develop factual knowledge of the discipline they are studying.

\section{Legal English skills and abilities}

The most significant skill which students following the English for Law course need to acquire if they are to cope with understanding, and at later stages, drafting legal texts is the skill of comprehension and interpretation.

Students have problems with understanding texts written in legalese due to lack of experience and insufficient language proficiency. Therefore, they need to be exposed to such texts in order to train their understanding and interpretation. In order to master these skills, students need to be familiarized with the structure (layout and format) of various legal documents, e.g. contracts, pieces of legislation, law suits, letters, legal memoranda, notices, etc. Samples of these documents can be accessed online or in books of templates such as e.g. "301 Legal Forms, Letters and Agreements" published by Lawpack Publishing (2007). When students are aware of how documents are structured, they can focus on reading and interpretation of their content. Students who come from countries with civil law jurisdiction are probably 
used to the purposive or teleological method of interpretation which determines the meaning upon the purpose of the contract, the intentions of the parties to the contract or the intention of the drafter of a piece of legislation.

In common law jurisdictions lawyers use the textual or literal method of text interpretation, i.e. they analyse only the words of the text and not any external evidence. This approach requires a great deal of pedantry, since here even where a comma is placed may make a difference to the interpretation of the text.

Modern English commercial contracts are usually structured on templates and there is a collection of clauses that are commonly found in their texts. These will include operative provisions, e.g. commencement, conditions precedent, payment terms etc. and so called boiler plate clauses including e.g. assignment, force majeure, acceleration etc., a clear overview of which can be found in Haigh (2012). Authentic samples of contract parlance constitute a base for language work that can include mastering the following skills:

I. Paraphrasing: the skill of paraphrasing mostly involves contrastive analysis of legalese and plain English and can be developed using the activities presented below in the Teaching Materials section.

II. Defining: the students need to be able to explain the meaning of legal terms or clauses contained in legislation or contracts in plain English, e.g. by using their synonyms, opposites, or formulating short and clear plain English definitions. In order to manage the task of defining successfully, students will have to develop extensive knowledge of legal terminology and then be trained in formulating the definitions which can be tested both ways, i.e. from plain English to legalese and vice versa. Legal English is characterised by certain linguistic peculiarities, which law students need to learn to understand:

a. "terms of art" which are technical words and phrases which have precise and fixed meaning as a legal term of art, but another meaning in ordinary English, e.g. consideration, construction, waiver, party, etc.

b. foreign terminology comprising Latin, e.g. per se, quorum, ultra vires, and French, e.g. force majeure, tenant, estoppel, words and phrases still used in legal English due to historical influences.

c. doublets, couplets and triplets of synonyms, e.g. null and void, terms and conditions, dispute, controversy or claim which illustrate the historic French influence and the shift to English when lawyers started to use both English and French words simultaneously in order to be understood. The modern tendency is to avoid them and 
to use one word instead of two or more. A comprehensible checklist of legalese undesirables comes as an appendix in Rylance (1994) together with preferred options for how they should be replaced.

d. here-, there- and where- words fulfilling the role of pronouns, used in legal English to avoid repetition, e.g. the parties hereto (to this contract) agree as follows, the premises and access thereto (to the premises). They are characteristic of the written language and their meaning often can be guessed from the context. Less experienced learners however, still need to train their usage and their meaning in the texts.

III. Translating: a task which is often assigned to job candidates to check their language proficiency is translation. Translation, even though for some people considered a thing of the past, develops and checks students' knowledge of vocabulary, grammar, the use of appropriate register and tone. Translations can be carried both ways - into English and into the students' native language, the latter usually appearing to be easier. Translations into the native language can accompany paraphrasing tasks for completion, in which students must first understand the exact meaning of the original text. When dealing with complex and highly formal texts, translation into the native language can serve as the first stage of the task.

IV. Summarising: this develops students' analytical, comprehension and paraphrasing skills as well as reading and writing skills. Students find it difficult to produce a brief but faithful summary of the original text using their own words. They must be taught how to use linking words to logically combine ideas, not to copy the original text and to include all the vital information in the summary.

V. Modern legal correspondence: a lawyer drafting a well laid out and linguistically excellent letter or e-mail builds an image of him/herself or of the law firm he/she is working for. Therefore, it is important to train students in drafting modern correspondence excerpts - and present them with up to date layouts and models of the most often used types of documents. They must also be equipped with the knowledge of standard phrases for letters, e-mails and memos. Before students start drafting full length letters themselves, they can start with writing e-mails and memos, which are usually shorter, less formal and easier to write. Later, the step by step approach can be adopted and students can be prepared for drafting letters by:

a. rearranging mixed up elements of the letters;

b. filling in gaps; 
Scaffolding the Writing Component of the English for Law Syllabus...

c. replacing excessively informal elements of letters with formal ones and vice versa;

d. drafting a letter following a chain of hints provided by the teacher and then making a comparison with a model provided by the teacher;

e. reducing the body of a letter into a chain of hints, which another student must expand back into a letter, etc.

An important element of any letter writing workshop is the issue of tone and politeness, which teachers should sensitize students to, since rudeness reflects badly on the image of the firm the author represents, as well as on him/her as an individual. Mastering the ability to apply the appropriate tone, depending on the situation and the recipient is crucial. A good writer will know what tone he/she should adopt for standard correspondence between lawyers, for letters to clients, for situations which require being firm, patient, decisive or sometimes tough.

A good writer is never aggressive, rude or disrespectful. Students, who are usually young and inexperienced, need to learn to understand that business correspondence is not a place in which to give vent to their emotions and may need a lot of practice in register/tone switching.

A good manual presenting modern layouts and standard phrases for plain English letters is the coursebook "The Lawyer's English Language Coursebook" by Catherine Mason and Rosemary Atkins (2011).

VI. Grammar for law: since excellent English and accuracy are most valued by internationally recognized employers, grammar cannot be undervalued in the English for Law syllabus even at higher levels of proficiency. Areas that are especially sensitive include:

a. questions (both direct and indirect), which can be especially useful in correspondence to add to the polite tone of the letter;

b. passive voice which, as has already been mentioned above, should be avoided, is still preferred by lawyers, as it is indirect and formal and in situations where the agent of the verb is unknown, the object is more important than the subject or when the writer wants to divert attention from the real subject, avoid giving specific information or the impression of being critical;

c. articles, which are a special problem area for Polish speakers;

d. countable and uncountable nouns, which include words often used incorrectly such as e.g. "*informations" or words which can be both countable and uncountable as e.g. paper (for the printer) vs. papers (research papers, newspapers) or liability (legal responsibility) vs. liabilities (financial liabilities); 


\section{Aleksandra Luczak}

e. word order, the mastering of which allows for structuring more complex sentences and linking clauses by means of prepositions and relative pronouns;

f. prepositions and their use in prepositional phrases, which amount to 296 as calculated by Mariusz Bęcławski in his Ph.D. research and presented in a paper entitled "The application of prepositions in legal English: theory and practice" delivered at the $3^{\text {rd }}$ International Legal English Conference held in Warsaw on 14 November 2009;

g. collocations and especially legally fixed collocations i.e. expressions, which have been used by generations of lawyers and changing them would create legal uncertainty;

h. negative prefixes (un-, in-, il-, im-, ir-, non- and anti-) and the difference between non- and un- as e.g. in non-statutory meaning "not found in statute" and unstatutory meaning "breaching a statute".

Modelling an English for Law syllabus is an eclectic process which stems from general and academic English experience. University students who follow English for Law courses are pre-experienced lawyers-to-be and will first need to build on transferable writing skills typical of academic writing before they proceed to the development of their future profession specific legal drafting. The art of syllabus design requires the teacher to select skills and activities that will help the students master their overall writer's workshop from the very beginning of the course, since only then will the students be able to move on to highly specialist legal drafting. The modern practical approach to legal writing requires that teachers draw on the experience of the still developing Plain English Movement. Their responsibility is to train their students to write in this modern, standard variety of English which has supplanted legalese. On the other hand, plain language is a style of communication in English that can be successfully transferred to academic or any other kind of writing. It postulates using language that is clear, concise, free of clichés and unnecessary jargon, that can be easily understood by laymen. Contemporary trends and changes that are observed in writing due to plain language postulates diminish the stress which teaching of writing for law brings. Legal writing in plain English is based on very simple rules: short, simple, omitting unnecessary words, favouring active voice over passive voice and verbs over nouns, following the S-V-O pattern, free of legal jargon. Students will learn to use the language to express, not to impress. It may take some time, but the students' prospective clients will appreciate the effort. 
Scaffolding the Writing Component of the English for Law Syllabus...

\section{Teaching materials}

Apart from the textbooks mentioned earlier in this section and included in the references, there are many online resources available which develop the skill of writing in plain English:

a. Plain language course on: http://www.faa.gov/about/initiatives/plain_ language/basic_course/ which teaches basic tools to help create plain language;

b. Plain Train on http://www.plainlanguagenetwork.org/plaintrain/ with tips and techniques for improving communication skills with the use of plain language;

c. Free guides on http://www.plainenglish.co.uk/free-guides.html offering advice on design and layout, writing letters, cv's and reports, glossary of alternative terms (or undesirables);

d. 39 rules for writing plain English by W. D. Lutz: http://www.plainlanguagenetwork.org/Resources/lutz.html;

e. A Plain English Handbook: http://www.sec.gov/pdf/handbook.pdf;

f. Free Plain English guides from Plain Language Commission on: http:// www.clearest.co.uk/pages/publications/freeguides;

g. Plain English Bibliography: http://www.scotland.gov.uk/Publications/ 2006/02/17093804/5.

h. Publication on common errors in English: http://public.wsu.edu/ $\sim$ brians/errors/

i. Garble's writing resources for plain English: http://home.comcast.net/ qgarbl/center/\#.Ui8bhYzwHDc

j. List of 75 online legal writing resources: http://goingpaperlessblog.com/ 2010/04/14/75-online-legal-writing-resources-just-in-time-for-summerassociates/

Examples of activities that can be prepared instantly and adopted into the legal English classroom:

a. Distribute a text written in legal English and ask students to find and replace all legalese "undesirables" with their plain English equivalents.

b. Distribute a text with bolded legalese phrases and ask students to replace all bolded phrases and words with their plain English equivalents.

c. Students paraphrase a contract clause / piece of legislation / etc. in one sentence / 10 words / 5 words / etc.

For homework students can be asked to prepare their version of the above assignments in the form of an e-mail to a friend who has asked for help in interpretation of legal documents. 
Aleksandra Euczak

a. Students read a text, then cover it up and paraphrase using their own words.

b. Students replace all colloquial phrases with legal English equivalents.

c. Students reconstruct a letter from hints, as in the example below:

This is the first letter from the solicitor Mark Odazc to the Client (Vera Boyle) following the initial client interview. In it the solicitor summarizes instructions he has been given by the client, advises on relevant issues, and indicates the steps that are needed to process the matter.

Please draft the letter in which you will:

i. Thank somebody or the meeting yesterday and for the details about the formation of a limited company under the name PerSe.

ii. Summarize the details: objects, authorised share capital (1,000 $£ 1$ shares), issued capital (51 shares to Vera, 49 to Elisabeth Carlini), who the company directors and company secretary will be, registered office (16 Torridon Road).

iii. Inform somebody what you have done to find out whether the name PerSe is currently registered.

iv. Inform somebody what documents you will need to draw up (Memorandum of Association, Articles of Association).

v. Explain why Vera will need a shareholders' agreement.

vi. Enclose a client care letter in duplicate and ask to sign, date and return it.

For this task teachers can use any well written letters they have available, e.g. 301 Legal Forms, Letters and Agreements (2007) or R. Haigh (2010). They should reduce the letter to the form of hints and then, after students have produced their versions, show the original letter as a model. Where there is no model letter, students can compare their versions and provide peer assessment.

Students read two different cases/problems and then one group writes a case brief and another summarizes their text in the form of an e-mail to a friend. Both groups try to give as detailed an account of the case as possible. Then students exchange their texts and for homework rewrite them, changing the register: a brief is now summarised in the form of an email, an e-mail becomes a formal letter.

Students solve a crossword. Student A receives a grid of a crossword and student $\mathrm{B}$ a list of down and across entries for the crossword. Student B paraphrases the entries in plain English, student A guesses the legal terms and fills in the crossword. Free online crossword makers can easily be 
googled: https://crosswordlabs.com/ or http://www.eclipsecrossword.com/ and many more.

Students create a glossary of legal English terms and their plain English equivalents, that can be published on the university website, e-learning platform or http://issuu.com/ in the form of a pdf booklet available as an open resource. The glossary can also be uploaded to http://www.memrise.com/ - a learning platform at which uploaded content can be practised in a variety of tasks automatically designed by the engine. A legal English vocabulary course has been started by the author of this paper and her students on http://www.memrise.com/user/LegalEnglish/.

\begin{tabular}{|l|l|l|l|}
\hline \multicolumn{1}{|c|}{ Legalese } & $\begin{array}{l}\text { Plain English synonym } \\
\text { or definition }\end{array}$ & Translation & \multicolumn{1}{c|}{ Remarks } \\
\hline null and void & not valid & nieważny & $\begin{array}{l}\text { doublet, choose one: } \\
\text { null or void }\end{array}$ \\
$\begin{array}{l}\text { construction of } \\
\text { the contract }\end{array}$ & $\begin{array}{l}\text { interpretation of } \\
\text { the contract }\end{array}$ & $\begin{array}{l}\text { interpretacja } \\
\text { umowy }\end{array}$ & \\
\hline
\end{tabular}

Students develop the Wikipedia list of plain English words and phrases on http://en.wikipedia.org/wiki/List_of_plain_English_words_and_phrases or create a similar resource using another wiki tool, e.g. Wikispaces on http://www.wikispaces.com/

\section{Conclusions}

Modelling and developing the writing component of the English for Law syllabus is necessary and beneficial, since the concerns about the deterioration in writing skills among university graduates are omnipresent. Unfortunately, in the case of legal education the coin has two sides. On the one hand, there have been postulates for writing reform and improved education for generations. On the other hand, lawyers write badly because doing so promotes their economic interests (...) and if lawyers stopped writing like lawyers, they might have trouble charging as much for their work (Stark, 1984:1389).

Language teachers can put aside politics and concentrate on the quality of education solely. Any ESP course will benefit from implementing the elements of plain English writing which can form the core of the syllabus for the development of the writing skill. Writing in plain language is nowadays 


\section{Aleksandra Luczak}

perceived as good writing. Plain language resources provide a step by step guidance on how to approach a writing task, structure paragraphs and create first drafts. They stress the need of redrafting, editing and proofreading which are so often neglected by the students.

Developing the skill of writing in plain English will teach the students planning, organization, and logic, as well as developing their analytical skills. It will demand that they use excellent English and have an advanced knowledge of legal English terms. All these elements can be transferred to any other environment in which written English is required, whether it is academic, business, etc.

Plain English writing course will have many beneficiaries. Students will learn how to produce well structured, clear and powerful texts. Their prospective readers will comprehend the texts at first reading and feel comfortable about signing documents they understand. Plain English classes will also be easier to teach by non-lawyer legal English teachers, who tend to declare that they feel intimidated by the complexity of legalese jargon.

The present paper has been an attempt to systematize knowledge about plain English and gather examples of good practice. It comprises a set of easily adopted ideas, which teachers can implement during their writing classes. It is hoped that it will inspire new ideas for teaching writing, including more writing activities in Legal English classes and syllabuses, and convince English teachers that teaching legal drafting is plain.

\section{R E F E R E N C E S}

301 Legal Forms. Letters and Agreements. (2007). London: Lawpack Publishing.

Atkins, R. \& Mason, C. (2007). The Lawyer's English Language Coursebook Global Legal English. Stamford: Global Legal English.

Butt, P. (2006). Modern Legal Drafting. A Guide to Using Clearer Language. Cambridge: Cambridge University Press.

Dickens, C. (2009). The Complete Works of Charles Dickens (in 30 volumes, illustrated): Bleak House, Vol. I. New York: Cosimo Classics.

Garner, B. A. (2001). Legal Writing in Plain English. A Text with Exercises. Chicago: The University of Chicago Press.

Górska-Poręcka, B. (2007). CEF Professional Law Profile: An Analysis of Lawyers' Professional Language and Communication Needs as a Source of Guidelines for University Language Teachers. The Teacher, 4.

Haigh, R. (2010). Oxford Handbook of Legal Correspondence. Oxford: Oxford University Press.

Haigh, R. (2012). Legal English. Third Edition. New York: Routledge. 
Scaffolding the Writing Component of the English for Law Syllabus...

Jordan, R. R. (1997). English for Academic Purposes: A Guide and Resource Book for Teachers. Cambridge: Cambridge University Press.

Munby, J. (1978). Communicative Syllabus Design. Cambridge: Cambridge University Press.

Oglivy, D. (2012). The Unpublished David Ogilvy. London: Profile Books Ltd.

Orwell, G. (1946). Why I write. London: Gangrel.

Orwell, G. (2013). Politics and the English Language. London: Penguin Books. (Original work published 1945).

Rylance, P. (1994). Legal Writing and Drafting. Oxford: Oxford University Press.

Stark, S. (Apr., 1984). Why lawyers can’t draft. Harvard Law Review. Volume 97, No. 6, 1389-1393.

Wallace, M. J. (2004). Study skills in English: a course in reading skills for academic purposes. Cambridge: Cambridge University Press. 